\title{
Seminal traits, suitability for semen preservation and fertility in the native Portuguese horse breeds Puro Sangue Lusitano and Sorraia: Implications for stallion classification and assisted reproduction
}

\author{
Sandra Gamboa ${ }^{\mathrm{a}, \mathrm{b}, *}$, Manuel Machado-Faria ${ }^{\mathrm{a}}$, João Ramalho-Santos ${ }^{\mathrm{b}}$ \\ a Animal Reproduction Laboratory, Department of Zootechnic Sciences, Agricultural School, Polytechnic Institute of Coimbra, \\ Bencanta, 3040-316 Coimbra, Portugal \\ b Department of Zoology, Center for Neuroscience and Cell Biology of Coimbra, University of Coimbra, 3004-517 Coimbra, Portugal
}

\section{A R T I C L E I N F O}

\section{Article history:}

Received 15 October 2007

Received in revised form 28 May 2008

Accepted 5 June 2008

Available online $\mathrm{xxx}$

\section{Keywords:}

Stallion

Lusitano

Sorraia

Semen

Cooled semen

Fertility

Equine

\begin{abstract}
A B S T R A C T
The Puro Sangue Lusitano (PSL) is the major national breed of horse in Portugal, but no studies exist on its seminal characteristics, or on the possibility of conserving semen for future use. The aim of this study was to evaluate semen parameters, fertility and the aptness to semen preservation in Lusitano Stallions. In order to compare characteristics defined by a single or by multiple semen collections per stallion 152 ejaculates obtained from 152 Lusitano stallions presented at an annual breeding soundness examination as well as data related to 371 ejaculates obtained from 9 PSL were analyzed. These latter samples were also evaluated in terms of their possible use in assisted reproduction and were compared with 113 ejaculates obtained from 4 Sorraia horses, a rare and endangered Portuguese breed. The percentage of motile spermatozoa (PMS) was assessed after collection (AC), after semen dilution (AD) and at $24 \mathrm{~h}$ of cool-storage. Mean values obtained for sperm motility and morphology and semen $\mathrm{pH}$ observed after semen collection differ significantly $(P<0.05)$ between single collection/multiple stallions and multiple collections/limited stallions, and no age related effects were detected. Overall, Lusitano semen quality was comparable to that of related breeds, while Sorraia stallions had very poor semen quality. The response to cool-storage of diluted semen samples differed among stallions and breeds, and the best results for progressive motile sperm cells at $24 \mathrm{~h}$ were in a range of $35-53 \%$ for PSL
\end{abstract}

\footnotetext{
* Corresponding author. Tel.: +351 239802 940/272; fax: +351 239802979.

E-mail address: scgamboa@esac.pt (S. Gamboa).
} 
stallions and were lower for Sorraia stallions. Fertility rates obtained with artificial insemination (AI) averaged at $85 \%$ for PSL. With the exception of PMS AC, sperm vitality and semen $\mathrm{pH}$ no other seminal trait seemed to influence fertility rates in the Lusitano breed.

(c) 2008 Elsevier B.V. All rights reserved.

\section{Introduction}

Although the equine species was probably the first to be subjected to artificial insemination (AI) (Allen, 2005) the use of modern assisted reproduction technologies in the horse industry has been slow by virtue of constraints imposed by some main horse breeding associations. Fortunately, this situation has changed, and the use of modern breeding techniques in the equine system has expanded worldwide.

In Portugal, an increased level of interest in AI has been registered in the past decade, with the goal to improve breeds and types of horses such as 'Português de Desporto' and 'Cruzado Português', both of which have the Lusitano breed (PSL) as an important contributor.

The Lusitano - a breed of horses native to the Iberian Peninsula and considered the oldest saddle horse in the world - is the product of thousands of years of selection, steeped in the tradition of its historical military links, bullfighting and the classical training methods of the "Haute École". The official institutionalization of the StudBook of the Lusitano Breed resulted in selection, by conditioning the admission of reproducers to the minimum morphological and functional requirements of the respective official breed standard. Male horses approved according to these criteria are subjected to semen collection and ejaculate examination. However, and despite these important efforts it should be noted that the standards used in semen evaluation derive from data obtained from other (diverse) breeds. In fact, the normal seminal traits in the PSL horse, against which new potential breeders should be compared, have yet to be well defined. This is extremely important, as significant breed-dependent variations have been reported, not only between light and draft horse breeds but also among Warmblood and Hotblood breeds (France, 1992). These differences relate to semen characteristics, namely semen volume, sperm motility and sperm concentration (Dowsett and Pattie, 1982; Dowsett and Knott, 1996; Paccamonti et al., 1999). The interval since a previous ejaculation(s), testicular size, and age can also be influential (Picket, 1993a,b). Furthermore, the age of a stallion affects gel-free seminal volume, total seminal volume and $\mathrm{pH}$ per ejaculate but not gel volume, motility or sperm concentration (Squires et al., 1979). Accordingly, Dowsett and Knott (1996) recommended that both the age and breed of a stallion be taken into consideration when evaluating semen, considering both breed and age of stallion had significant effects on fertility (Dowsett and Pattie, 1982).

Procedures for assessing suitable breeding potential have been developed and two types of evaluations are used: (1) analysis of a minimum of two ejaculates obtained $1 \mathrm{~h}$ apart; (2) analysis of two ejaculates collected $1 \mathrm{~h}$ apart, then single ejaculates collected daily for 6 or 7 days. The latter is considered more informative and would predict with reasonable accuracy the daily sperm output, and thus the number of mares that may be bred (Picket, 1993a,b) by natural mating or by AI.

Seminal collection with an artificial vagina allows the evaluation of seminal quality before $\mathrm{AI}$ and assists in early detection of infertility problems in the stallion (Brinsko and Varner, 1993). Furthermore, the use of AI provides, besides hygienic and sanitary advantages, an efficient use of the stallion by virtue of the employment of semen extenders, which can improve the fertility rates of some subfertile stallions (Batellier et al., 2001). Together with semen cooling, these techniques allow the extended use, storage and transport of specific stallion semen samples. This is important given that a horse's career may not be compatible with its use during the classical breeding season. However, the use of artificial reproduction technologies (ART) introduces yet another set of variables in horse breeding, as several breed-dependent characteristics have been reported (Dowsett and Pattie, 1982; Parlevliet and Colenbrander, 1999; Parlevliet et al., 1994; Aurich et al., 2003).

Thus, it is not only relevant to properly ascertain stallion semen characteristics comparing a sample with a standard from the same breed, but also to determine its ability to be used in ART, again comparing data obtained specifically for this breed. To our knowledge both these things are lacking not only for 
the Lusitano but also for another native Portuguese horse breed, the Sorraia horse. This critically endangered breed, with an extremely reduced effective population $(<200$ animals from which around 80 are breeding mares; Luís et al., 2007), share a common female founder with the Lusitano breed (Luís et al., 2006). Inbreeding is common in Sorraia horses and its effect, especially in small populations, is commonly assumed to negatively affect fertility (Klemetsdal and Johnson, 1989) and/or semen quality (van Eldik et al., 2006).

This paper thus focuses on seminal traits, quality and aptness for preservation (semen cooling) of ejaculates from Lusitano and Sorraia stallions. With this work we intend to contribute towards the standard definition of seminal traits in these breeds in relation to data already available for other breeds, as well as their aptness to be used in modern artificial reproduction technologies.

\section{Material and methods}

\subsection{Animals and study design}

Data concerning to analysis of semen obtained from PSL male horses were used in this report and explored in two different strategies. Thus, we analyzed ejaculates collected since 1993 at the Animal Reproduction Laboratory (Agricultural School of Coimbra, Portugal), from stallions that were subject to breeding soundness examination (a single collection per stallion/multiple stallions) during the nonbreeding season (October-November) and from stallions, with or without a history of normal fertility but approved to reproduction by the Stud Book (multiple collections per stallion/limited number of stallions). The animals were located at the Agricultural School, Polytechnic Institute of Coimbra (Coimbra, Portugal $-40^{\circ} 12^{\prime} 54.3^{\prime \prime} \mathrm{N}$ and $00^{\circ} 41^{\prime} \mathrm{E}$ ) and were kept in boxes on straw, with water freely available, and fed hay and food three times a day.

The ejaculates were obtained using a Hannover or INRA model artificial vagina (France, 1992) with each stallion mounted on an oestrus mare (single collection/multiple stallions) or a phantom (Hannover model, Multiple collections) with a teaser mare standing in the collection room. Number of mounts leading to ejaculation was annotated for data from multiple collections/limited stallions. Throughout the same time period we also performed semen collections from four Sorraia horses and those data were used for comparison with Lusitano stallions.

Immediately after dismount the raw ejaculates were brought to the laboratory and filtered through sterile gauze to remove the gel and any large particles of debris. The gel-free semen was immediately assessed for colour, smell and general appearance (aspect) and maintained at $35^{\circ} \mathrm{C}$ in a water-bath during seminal evaluation and handling. Semen volume and $\mathrm{pH}$ were also registered.

Seminal characteristics from Lusitano stallions defined by one single collection per stallion.

\subsection{Seminal characteristics from Lusitano stallions defined by one single collection per stallion}

Semen data were analyzed retrospectively from semen evaluation records $(n=152)$ of 152 stallions (ranged in age between 3 and 12 years old) during the last 14 non-breeding seasons. Once a previous analysis (ANOVA) failed to show differences related to stallions age we organize data considering not only the results obtained by Amann et al. (1979), Thompson et al. (1979) and Squires et al. (1979) but also stallion utilization frequency, as suggested by Picket (1993a,b). Thus, five aged sub-groups were constituted considering younger (group $1-3$ and 4 years old, $n=25$ ), mature (group 2-5 years old, $n=44$; group 3-6 years old, $n=27$; group $4-7$ and 8 years old, $n=21$ ) and old stallions (group $5->9$ years old, $n=26$ ).

\subsection{Seminal characteristics defined by multiple semen collections per stallion; semen application and preservation}

Data were analyzed retrospectively from semen evaluation records $(n=484)$ obtained during the breeding seasons (February-July) and distributed as follow: 9 Lusitano stallions (4- to 21-year-old), $n=371$ ejaculates (PSL 1, $n=46$; PSL 2, $n=36$; PSL 3, $n=84$; PSL 4, $n=11 ;$ PSL 5, $n=48 ;$ PSL 6, $n=17$; PSL 
7, $n=29$; PSL 8, $n=36$; PSL 9, $n=64$ ) and 4 Sorraia stallions (4-13-year-old), $n=113$ ejaculates (Sorraia $1, n=8$; Sorraia 2, $n=28$; Sorraia 3, $n=64$; Sorraia 4,n=13).

Semen was diluted in a milk-extender (liquid ultra heat treatment - UHT - half-skim milk) and standard doses $\left(10 \mathrm{ml} ; 20 \times 10^{6} \mathrm{PMS} / \mathrm{ml}\right)$ of diluted semen were fractionated in each of three $10 \mathrm{ml}$ centrifuge tubes that were then packed into $50 \mathrm{ml}$ tubes and stored under anaerobic conditions in a refrigerator for $24 \mathrm{~h}$ at $4{ }^{\circ} \mathrm{C}$. Following this incubation time sperm motility was examined.

Semen doses for immediate AI were also prepared as describe before (Gamboa and Ramalho-Santos, 2005) and a total of 197 mares had been inseminated within $1 / 2-1 \mathrm{~h}$ after semen collection with $300 \times 10^{6}$ PMS suspended in $15 \mathrm{ml}$ of the milk-extender.

Ovaries of the mares used in AI were scanned (Aloka SSD-500 V, Probe $5 \mathrm{MHz}$ transducer-ALOKA CO., Ltd., Japan) from the onset of oestrus every $48 \mathrm{~h}$. When a $35-\mathrm{mm}$ follicle was observed, females were artificially inseminated every other day until ovulation.

For pregnancy diagnosis and twining inspection ultrasonographic images of the conceptus between 13 and 16 days after last AI were taken. Due to embryonic loss in early pregnancy this examination was repeated at day 45 .

To calculate the fertility rates (fertility per cycle [FC], fertility at the end of the breeding season [FBS]) and after foaling (RF) we used the estimations and rules commonly employed in French National Studies (France, 1992) and previously described (Gamboa and Ramalho-Santos, 2005).

\subsection{Semen evaluation}

Sperm motility was assessed using a phase contrast microscope (Laborlux, Leica; equipped with a heating stage) at the time of collection and the percentage of total progressive motile spermatozoa (PMS) was estimated visually by the observation of 5-10 microscopy fields in each of two drops ( $5.5 \mu \mathrm{l}$ each drop) of raw semen. Filtered semen was diluted $20 \times$ (semen with few sperm cells) or $40 \times$ (semen with more spermatozoa) in formal saline solution to assess sperm concentration using a photocolourimeter ( $\lambda=546 \mathrm{~nm}$; Colorimeter 254, Ciba-Corning). An aliquot of sperm was mixed with eosin-nigrosin on a slide for vitality evaluations (Bloom, 1950) as well as with India ink for sperm morphology analysis (Foote, 2003). Two hundred cells were assessed for each slide using bright-field microscopy (Laborlux, Leica) in 20-50 microscopy fields.

\subsection{Statistical analysis}

The statistical analysis was performed using the SPSS version 14.0 software (SPSS, Inc., Chicago, IL, USA). All the samples data were checked for normal distribution and homogeneity of variances to decide between parametric or non-parametric tests. Once the assumptions behind the standard one-way multivariate analyzes of variance (MANOVA) were shown not to be invalid for homogeneity of variances, we used this parametric procedure designed to test for the significance, at a 95\% level, of the differences between the multiple age sub-groups (single collections/multiple stallions). The Spearman's correlation coefficient was used as an association measurement between seminal traits. Differences were considered statistically significant when $P \leq 0.05$ (Maroco, 2007).

For the data set related to multiple collections/limited stallions a multivariate analyzes of variance (MANOVA) was used to analyze effects of stallion, breed and number of mounts on seminal traits. In the case of rejection of $H_{0}$ (mean values of seminal traits were equal among stallions and among number of mounts to ejaculation) the Kruskal-Wallis test followed by a multiple comparison of the orders means by the Fisher's LSD test (Maroco, 2007) was applied to compare stallions and number of mounts while the Wilcoxon-Mann-Whitney test was applied to compare breeds. The coefficient of variation (\%) was used to express variation of sperm parameters among stallions. Interaction of stallion and number of mounts until ejaculation on seminal traits was analyzed using general linear model (GLM). To test the influence of number of mares bred per stallion, number of mounts until ejaculation and sperm characteristics on fertility an analysis of covariance was used. To compare sperm motility after collection (PMS AC), after dilution (PMS AD) and after $24 \mathrm{~h}$ of conservation (PMS $24 \mathrm{~h}$ ) the Friedman's non-parametric test followed by a multiple comparison of the orders means, as described in Maroco (2007), was used. Differences were considered statistically significant when $P \leq 0.05$ (Maroco, 2007). 


\section{Results}

\subsection{Seminal characteristics from Lusitano stallions defined by one single collection per stallion}

From a total of 158 stallions selected for seminal assessment at the breeding soundness evaluation, 152 were effectively collected while the remaining 6 were not able to jump the mare. All semen samples were obtained in the Fall, and no significant differences were found when considering the different age subgroups (data not shown). The determination of the central tendency, dispersion, kurtosis and skewness measures for seminal traits are shown in Table 1.

In general, asymmetric, leptokurtic distributions ( $\mathrm{g} 2>0$, i.e., a sharp distribution) were observed for sperm concentration ( $\mathrm{g} 1>0$, i.e., positively skewed), vitality ( $\mathrm{g} 1<0$, i.e., negatively skewed) and normal sperm morphology ( $\mathrm{g} 1<0)$; semen volume ( $\mathrm{g} 1>0), \mathrm{pH}(\mathrm{g} 1>0)$ and sperm motility $(\mathrm{g} 1<0)$ presented asymmetric and mesocurtic distributions (g2 $\approx 0$, i.e., without flattening). Mean values ( \pm S.D.) for stallion semen characteristics were determined (Table 1). Between the three main structural regions considered in the evaluation of sperm morphology, the midpiece region presented more alterations $(12.57 \pm 9.91 \%)$ followed by the head $(8.25 \pm 7.54 \%)$ and by the tail $(4.39 \pm 5.34 \%)$. Checking the spread of data around the mean we observed that semen volume and sperm concentration varied more widely.

Association measurements determined by Spearman's correlation coefficient showed a negative and strong relationship between seminal volume and sperm concentration $(P<0.05)$. We checked also for correlations between the other sperm parameters and found that sperm motility did yield slight but significant $(P<0.001)$ positive correlation coefficients with sperm vitality $(r=0.39)$ and with normal morphology $(r=0.38)$.

\subsection{Seminal characteristics defined by multiple semen collections from Lusitano and Sorraia stallions}

When considering the use of stallion semen for preservation and ART multiple samples are collected from selected breeding males. Interestingly when comparing this approach (371 ejaculates from 9 Lusitano stallions) to the previous one (152 ejaculates from 152 stallions), although seminal parameters showed similar overall values at first glance (Table 1 ), there were significant differences for progressive motile sperm after collection (PMS AC), morphologically normal sperm and $\mathrm{pH}(P<0.05)$. On the other hand, all seminal parameters for the Sorraia breed (multiple collections/stallion) differed significantly $(P<0.05)$ from PSL whatever the collection strategy applied to the former breed. Furthermore the quality of Sorraia semen was noticeably poorer, in terms of sperm motility, vitality and morphology (Table 1 ). In this case there were many sperm head defects, related with the dimensions of the sperm heads (both very small and very large sperm heads, data not shown).

When considering multiple collections/stallion for both breeds an average of $1.49 \pm 0.72$ mounts led to ejaculation in the Lusitano stallions and $1.48 \pm 0.75$ in Sorraia stallions, suggesting that there are no particular difficulties in obtaining samples from these animals. For PSL stallions, in 371 valid cases we obtained $62.5 \%$ of the ejaculates at first mount (232/371), $27.5 \%$ at the second (102/371), equal to what was recorded for Sorraia horses [63.7\% of the ejaculates at first mount (72/113), $28.3 \%$ at the second (32/113)].

There was a significant $(P<0.05)$ inter-stallion variation (expressed as coefficient of variation) found in PSL and Sorraia stallions superior to the level of intra-stallion variation observed in all sperm parameters (Table 2). On the other hand, seminal parameters were affected by the individual stallion factor $(P<0.05)$, while the number of mounts affected qualitative and quantitative seminal characteristics in a minor way (Table 2).

Ejaculates from PSL did not differ significantly with increasing number of mounts but a distinction was noted for Sorraia horses (data not shown). Ejaculates obtained with the first mount showed smaller volumes when compared with ejaculates collected after the second and third mounts in both native Portuguese breeds. However in PSL ejaculates no correlation was found between the number of mounts to ejaculation and semen volume (data not shown). In contrast, for Sorraia stallions this volume increment was concomitant with a decrease in sperm concentration $(r=0.40, P<0.001)$ not observed in PSL (data not shown). 


\section{Table 1}

Descriptive statistics for seminal traits in PSL (multiple stallions, single collections ${ }^{\mathrm{a}}$ and limited stallions, multiple collections ${ }^{\mathrm{b}}$ ) and Sorraia horses ${ }^{\mathrm{c}}$

\begin{tabular}{|c|c|c|c|c|c|c|c|c|c|c|}
\hline & \multirow{2}{*}{$\begin{array}{l}\text { Gel free } \\
\text { volume } \\
(\mathrm{ml})\end{array}$} & \multirow{2}{*}{$\begin{array}{l}\text { Sperm con- } \\
\text { centration } \\
\left(\times 10^{6}\right)\end{array}$} & \multirow[t]{2}{*}{$\operatorname{TSN}\left(\times 10^{9}\right)$} & \multirow[t]{2}{*}{ PMS ACd $(\%)$} & \multirow{2}{*}{$\begin{array}{l}\text { Sperm } \\
\text { vitality }^{\mathrm{e}}(\%)\end{array}$} & \multirow{2}{*}{$\begin{array}{l}\text { Normal mor- } \\
\text { phological } \\
\text { sperm }^{f}(\%)\end{array}$} & \multicolumn{3}{|c|}{ Altered morphological sperm ${ }^{\mathrm{f}}$} & \multirow[t]{2}{*}{ Semen $\mathrm{pH}$} \\
\hline & & & & & & & $\begin{array}{l}\text { Sperm head } \\
(\%)\end{array}$ & $\begin{array}{l}\text { Sperm } \\
\text { mid-piece (\%) }\end{array}$ & $\begin{array}{l}\text { Sperm tail } \\
(\%)\end{array}$ & \\
\hline \multicolumn{11}{|l|}{$\mathrm{PSL}^{\mathrm{a}}$} \\
\hline Mean & $41.72 \mathrm{a}$ & $241.26 \mathrm{a}$ & $8.34 \mathrm{a}$ & $41.60 \mathrm{a}$ & $69.27 \mathrm{a}$ & $74.52 \mathrm{a}$ & $8.25 \mathrm{a}$ & $12.57 \mathrm{a}$ & $4.39 a$ & $7.45 a$ \\
\hline S.D. & 23.72 & 166.35 & 5.58 & 16.58 & 17.60 & 13.44 & 7.54 & 9.91 & 5.34 & 0.42 \\
\hline Kurtosis & -0.67 & 2.01 & 2.58 & -0.26 & 0.63 & 2.83 & 23.61 & 4.93 & 12.21 & -0.13 \\
\hline Skewness & 0.48 & 1.45 & 1.47 & -0.06 & -0.88 & -1.35 & 3.69 & 1.98 & 3.13 & 0.13 \\
\hline$N$ & 152 & 152 & 152 & 152 & 130 & 139 & 139 & 139 & 139 & 152 \\
\hline PSL $^{\mathrm{b}}$ & $\begin{array}{l}46.78 \pm 28.91 \\
(360) \mathrm{a}\end{array}$ & $\begin{array}{l}217.07 \pm 133.03 \\
(371) \mathrm{a}\end{array}$ & $\begin{array}{l}8.61 \pm 5.13 \\
(360) \mathrm{a}\end{array}$ & $\begin{array}{l}46.70 \pm 11.91 \\
(371) b\end{array}$ & $\begin{array}{l}68.15 \pm 19.97 \\
(290) \mathrm{a}\end{array}$ & $\begin{array}{l}77.78 \pm 15.64 \\
(283) b\end{array}$ & $\begin{array}{l}9.71 \pm 11.32 \\
(283) \mathrm{a}\end{array}$ & $\begin{array}{l}7.89 \pm 6.12 \\
(283) b\end{array}$ & $\begin{array}{l}4.63 \pm 5.39 \\
(283) \mathrm{a}\end{array}$ & $\begin{array}{l}7.33 \pm 0.38 \\
(339) \mathrm{b}\end{array}$ \\
\hline Sorraia & $\begin{array}{l}21.64 \pm 14.44 \\
(95) b\end{array}$ & $\begin{array}{l}232.15 \pm 140.68 \\
(113) b\end{array}$ & $\begin{array}{l}4.11 \pm 2.26 \\
(95) \mathrm{b}\end{array}$ & $\begin{array}{l}20.71 \pm 9.34 \\
(113) c\end{array}$ & $\begin{array}{l}41.41 \pm 16.75 \\
(102) b\end{array}$ & $\begin{array}{l}51.47 \pm 16.57 \\
(99) \mathrm{c}\end{array}$ & $\begin{array}{l}19.94 \pm 12.37 \\
(99) \mathrm{b}\end{array}$ & $\begin{array}{l}10.15 \pm 6.22 \\
(99) c\end{array}$ & $\begin{array}{l}18.43 \pm 9.07 \\
(99) b\end{array}$ & $\begin{array}{l}7.48 \pm 0.40 \\
(109) c\end{array}$ \\
\hline
\end{tabular}

The semen samples were examined immediately after collection. For each ejaculate counts were performed on 200 cells. For each ejaculate counts were performed on 200 cells. In each column values with different letters $(\mathrm{a}-\mathrm{c})$ differ significantly $(P<0.05)$.

a $n=152$, a single ejaculate per stallion.

b $n=371$, multiple ejaculates per each of 9 stallions.

c Values are mean \pm S.D. of measurements.

d Progressive motility sperm observed after collection.

e Values are mean ( \pm S.D.) percentages of the viable (not eosin stained) cells.

${ }^{\mathrm{f}}$ Values are mean $( \pm$ S.D.) percentages of the cells that had abnormal morphology. 
Table 2

Intra- and inter-stallion variation, according with each breed, of sperm composition expressed as coefficient of variation and interaction of stallion and number of mounts until ejaculation on sperm characteristics analyzed using linear models (GLM) during the breeding season (9 PSL stallions and 4 Sorraia stallions)

\begin{tabular}{|c|c|c|c|c|c|c|}
\hline & \multicolumn{2}{|c|}{ Coefficient of variation (\%) } & \multirow{2}{*}{$\begin{array}{l}\text { Goodness-of-fit } \\
R^{2}\end{array}$} & \multicolumn{3}{|c|}{ Effect of. ..(factors) } \\
\hline & Intra-stallion & Inter-stallion & & Stallion (\%) & Number of Mounts (\%) & Stallion $x$ number of mounts (\%) \\
\hline \multicolumn{7}{|l|}{ PSL } \\
\hline Semen volume (ml) & 54 & 62 & 0.37 & 19 & 0.3 & 9.4 \\
\hline Sperm concentration $\left(\times 10^{6}\right)$ & 47 & 61 & 0.43 & 25 & 2.8 & 14.1 \\
\hline $\operatorname{TSN}\left(\times 10^{9}\right)$ & 53 & 65 & 0.25 & 16 & 0.6 & 7.0 \\
\hline Sperm vitality (\%) & 22 & 29 & 0.51 & 34 & 0.8 & 3.9 \\
\hline PMS AC (\%) & 29 & 38 & 0.41 & 27 & 1.0 & 6.2 \\
\hline Morphological normal sperm (\%) & 12 & 20 & 0.55 & 39 & 0.8 & 10.9 \\
\hline $\mathrm{pH}$ & 5 & 5 & 0.23 & 11 & 1.0 & 4.1 \\
\hline \multicolumn{7}{|l|}{ Sorraia } \\
\hline Semen volume (ml) & 53 & 67 & 0.35 & 16 & 5.5 & 5.9 \\
\hline Sperm concentration $\left(\times 10^{6}\right)$ & 41 & 61 & 0.34 & 5 & 7.3 & 2.1 \\
\hline $\operatorname{TSN}\left(\times 10^{9}\right)$ & 53 & 55 & 0.22 & 17 & 0.6 & 4.6 \\
\hline Sperm vitality (\%) & 35 & 41 & 0.28 & 16 & 3.9 & 5.1 \\
\hline PMS AC (\%) & 43 & 45 & 0.37 & 26 & 0.3 & 1.8 \\
\hline Morphological normal sperm (\%) & 27 & 33 & 0.43 & 25 & 4.6 & 8.6 \\
\hline $\mathrm{pH}$ & 5 & 5 & 0.23 & 13 & 0.9 & 5.7 \\
\hline
\end{tabular}


Table 3

Effects of number of mares bred per stallion and sperm characteristics on per cycle fertility (FC) and fertility at the end of the breeding season (FBS) based on multifactorial analysis of covariance (13 stallions)

\begin{tabular}{|c|c|c|c|c|}
\hline & \multicolumn{4}{|c|}{$P$-value } \\
\hline & \multicolumn{2}{|l|}{ FC } & \multicolumn{2}{|l|}{ FBS } \\
\hline & $\mathrm{PSL}^{\mathrm{a}}$ & Sorraia ${ }^{b}$ & PSL & Sorraia \\
\hline Number of mares booked per stallion & 0.133 & 0.000 & 0.095 & 0.010 \\
\hline Number of mounts & 0.040 & 0.000 & 0.036 & 0.000 \\
\hline Seminal volume (ml) & 0.693 & 0.379 & 0.015 & 0.267 \\
\hline Sperm concentration $\left(\times 10^{6}\right)$ & 0.227 & 0.298 & 0.032 & 0.202 \\
\hline $\operatorname{PMS~AC}{ }^{\mathrm{C}}(\%)$ & 0.000 & 0.027 & 0.001 & 0.067 \\
\hline PMS AD ${ }^{\mathrm{d}}(\%)$ & 0.302 & 0.248 & 0.152 & 0.483 \\
\hline Sperm vitality ${ }^{\mathrm{e}}(\%)$ & 0.012 & 0.604 & 0.001 & 0.567 \\
\hline Normal morphological sperm ${ }^{\mathrm{f}}$ & 0.496 & 0.689 & 0.485 & 0.540 \\
\hline Semen $\mathrm{pH}$ & 0.000 & 0.002 & 0.000 & 0.001 \\
\hline
\end{tabular}

The semen samples were examined immediately after collection. For each ejaculate counts were performed on 200 cells. For each ejaculate counts were performed on 200 cells.

a $n=371$ semen samples; multiple ejaculates per each of 9 stallions.

b $n=113$ semen samples; multiple ejaculates per each of 4 stallions.

c Progressive motility sperm observed after collection.

d Progressive motility sperm observed after semen dilution.

e Viable (not eosin stained) cells.

f Normal cells morphology.

\subsection{Preservation and application of Lusitano and Sorraia semen}

A total of 323 ejaculates were processed for AI (PSL, $n=268$; Sorraia, $n=55$ ) and 198 of them (PSL, $n=184$; Sorraia, $n=14$ ) were also subjected to liquid storage at $4{ }^{\circ} \mathrm{C}$ in a milk-extender (half-fat commercial superheated UHT milk). After semen dilution, sperm motility in PSL increased (mean value $10.06 \%, P<0.05$ ) and was significantly reduced after $24 \mathrm{~h}$ at $4{ }^{\circ} \mathrm{C}$. A similar effect was detected for Sorraia $(P<0.05)$. The response to cool-storage of diluted semen samples also differed among stallions $(P<0.05$, data not shown). Importantly significant differences were found between PSL and Sorraia for the length of sperm survival measured as PMS after storage at $4{ }^{\circ} \mathrm{C}$, with the Sorraia breed showing poorer preservation ability $(P<0.05)$. These differences were especially clear in terms of sperm motility ( $31.52 \pm 16.50 \%$ for PSL; $11.79 \pm 7.23 \%$ for Sorraia).

Strong and significant correlations were found in PSL breed between sperm motility after collection and sperm motility after dilution $(r=0.89, P<0.001)$, similarly to what happened in Sorraia horses $(r=0.80, P<0.001)$. Conversely, in Lusitano stallions, PMS $24 \mathrm{~h}$ was not correlated with PMS AC, while in Sorraia stallions a strong and significant correlations was found $(r=0.55, P<0.001)$. Sperm motility after collection and sperm motility after dilution in Lusitano stallions also correlated with sperm vitality ( $r=0.62, P<0.001$ and $r=0.59, P<0.001$, respectively), negatively with abnormal sperm heads $(r=-0.43, P<0.001$ and $r=-0.50, P<0.001$, respectively) and with abnormal sperm tails $(r=-0.28$, $P<0.001$ and $r=-0.19, P<0.05$, respectively) contrary to Sorraia horses, where these correlations were not evident (data not shown). Sperm vitality also correlated negatively with abnormal sperm heads $(r=-0.39, P<0.001)$ and with abnormal sperm tails $(r=-0.37, P<0.001)$. Correlations between sperm motility after $24 \mathrm{~h}$ of conservation at $4{ }^{\circ} \mathrm{C}$ and motility after dilution $(r=0.21, P<0.001)$ and between semen $\mathrm{pH}(r=-0.18, P<0.05)$ as well sperm vitality between abnormal sperm mied-piece $(r=-0.15$, $P<0.05)$ were lower but significant in PSL.

\subsection{Fertility rates}

A total of 197 mares were booked for the 2 breeds as follow: 178 mares for PSL stallions $(9.15 \pm 4.70$ in average), and 19 for Sorraia horses $(3.20 \pm 2.52)$. The mean values for per cycle fertility rates (FC) and for fertility at the end of the breeding season (FBS) in PSL stallions were: 
Table 4

Range of normal values for seminal characteristics of stallion semen from a variety of breeds

\begin{tabular}{|c|c|c|c|c|}
\hline Semen volume (ml) & Sperm concentration $\left(\times 10^{6} / \mathrm{ml}\right)$ & Mob AC (\%) & Vitality (\%) & Reference \\
\hline $30-300$ & $30-600$ & 40 & 65 & Davis-Morel, 1999 \\
\hline $20-60$ & $\geq 73$ & $\geq 55$ & $66-86$ & $\begin{array}{l}\text { Light horse breeds (France, } \\
\text { 1992) }\end{array}$ \\
\hline 33-99 & $\geq 28$ & $\geq 31$ & & $\begin{array}{l}\text { Draft horse breeds (France, } \\
\text { 1992) }\end{array}$ \\
\hline 28 & 114 & $70-72$ & $78-80$ & $\begin{array}{l}\text { Troroughbred (Dowsett and } \\
\text { Knott, 1996) }\end{array}$ \\
\hline 30 & 97 & $78-80$ & $84-86$ & $\begin{array}{l}\text { Standardbred (Dowsett and } \\
\text { Knott, 1996) }\end{array}$ \\
\hline 36 & 286 & $84-86$ & $89-91$ & $\begin{array}{l}\text { Arabian(Dowsett and Knott, } \\
\text { 1996) }\end{array}$ \\
\hline $40-50$ & $>200$ & $60-70$ & $70-80$ & $\begin{array}{l}\text { Pura Raza Española (Chapa, } \\
\text { 1992) }\end{array}$ \\
\hline 33 & 116 & $77-79$ & $82-84$ & $\begin{array}{l}\text { Australian Stock Horse } \\
\text { (Dowsett and Knott, 1996) }\end{array}$ \\
\hline 24 & 171 & $73-75$ & $75-78$ & $\begin{array}{l}\text { Quarter Horse (Dowsett and } \\
\text { Knott, 1996) }\end{array}$ \\
\hline 24 & 138 & $72-74$ & $78-80$ & $\begin{array}{l}\text { Palomino (Dowsett and Knott, } \\
\text { 1996) }\end{array}$ \\
\hline 21 & 104 & $69-71$ & $74-76$ & Pony (Dowsett and Knott, 1996) \\
\hline 44 & 101 & $69-71$ & $61-63$ & $\begin{array}{l}\text { Shetland (Dowsett and Knott, } \\
\text { 1996) }\end{array}$ \\
\hline 23 & 90 & $72-74$ & $83-86$ & $\begin{array}{l}\text { Appalosa (Dowsett and Knott, } \\
\text { 1996) }\end{array}$ \\
\hline $23-25$ & $222-245$ & $63-64$ & & $\begin{array}{l}\text { Miniature stallions } \\
\text { (Paccamonti et al., 1999) }\end{array}$ \\
\hline $31-71$ & $37-375$ & $59-77$ & $51-81$ & $\begin{array}{l}\text { Dutch Warmblood stallions } \\
\text { (Parlevliet et al., 1994) }\end{array}$ \\
\hline
\end{tabular}

$\mathrm{FC}=69.73 \pm 20.39 \%$ and $\mathrm{FBS}=85.68 \pm 17.10 \%$. These rates were significantly $(P<0.001)$ different from Sorraias (FC $=20.52 \pm 15.29 \%$ and FBS $=34.07 \pm 23.40 \%$ ) but in both Portuguese breeds the stallion factor has a significant influence in fertility rates $(P<0.001)$. In general, stallion behaviour at semen collection, PMS AC and semen pH affected fertility in both breeds. In Sorraia horses, semen volume and sperm concentration showed statistically significant influence on per cycle fertility (Table 3).

\section{Discussion}

As part of the procedure to select Lusitano stallions for breeding, male horses are subjected to a single semen collection and the respective ejaculates examined for sperm quality. The minimum age required is 3 years old (the end of puberty) but older stallions can also be evaluated. Little is known about the seminal characteristics of Lusitano stallions and the aptitude of sperm cells to support the low temperatures used in semen technology.

In the equine species, the age at puberty ranges from 56 to 97 weeks, averaged at 83 weeks (Naden et al., 1990) and the maximum reproductive capacity, i.e., sexual maturity, is achieved 2-4 years later, since testicular size and daily sperm production increase for several years after puberty (Johnson et al., 1991).

We have retrospectively analyzed 152 ejaculates from 152 Lusitano stallions, ranging in age from 3 to 12 years old. Samples were obtained since 1993 from a single laboratory and the methods of semen collection and semen analysis were constant over the study period. There was no age effect for the seminal trait means analysed, contrary to what was obtained by Johnson et al. (1991), but similar to the results reported by Squires et al. (1979). Despite the lack of a clear age effect, data analyses fit a significant positive relationship between sperm motility and sperm vitality as well as between sperm motility and morphology as described by others (Voss et al., 1982). 
When considering data concerning the seminal parameters of a variety of horse breeds (Table 4) our results show that Lusitano semen characteristics place them at the high end of the spectrum (high concentration, motility and vitality), whilst Sorraia stallions show very poor sperm motility and vitality.

The mean values obtained for seminal traits for Lusitano stallions are similar to those obtained by Chapa (1992) in the Spanish purebred (Pura Raza Española), which is not surprising considering that these two breeds only differ by the recent selection criteria used in both countries (Oom, 1992). Indeed, one of the mitochondrial DNA haplogroups studied in the Lusitano breed, which represents half of the Lusitano maternal lines, is characteristic of horses from the Iberian Peninsula and Northern Africa (Royo et al., 2005; Luís et al., 2006).

From the data obtained we can infer that a single ejaculate is not enough to properly evaluate semen quality especially if it will rely on sperm motility and morphology (Pattie and Dowsett, 1982). Indeed, when the nine Lusitano males were thoroughly studied, the effect of stallion on seminal traits was significant for all seminal parameters. Similarly to what was reported by Sieme et al. (2004) we also found a degree of intra-stallion variation in sperm characteristics lower than the degree of interstallion variation in the two Portuguese breeds. The stallion factor also clearly influenced the variations found in sperm parameters for Sorraia horses. However, the proportion of total variability attributable to stallion factor, as well as the coefficient of determination, was lower in our results when compared with Sieme et al. (2004).

The data also shows that the number of mounts does not markedly affect seminal parameters or the longevity of sperm survival, and that per cycle FC were not affected by unsuccessful semen attempts.

Sperm motility mean values obtained in both approaches for PSL stallions were close to $50 \%$, a value required to approve a stallion in a seminal evaluation. However, the relationship between motility and fertility is far from clear (Rodriguez-Martinez, 2003) and, in this study, the PSL stallion with poorest sperm motility was highly fertile.

The main morphological alterations in Lusitano sperm were at the mid-piece region. In contrast, in the Sorraia horses the main morphological alteration was observed at the sperm head region, related with abnormal sperm head size. Conflicting correlations have been reported between sperm morphology and the fertility of fresh stallion semen (see Malmgren, 1992 for a review). Bielański and Kaczmarski (1979) postulated that $>10 \%$ of sperm primary morphological alterations were always suggestive of lowered fertility while $>30 \%$ of secondary abnormalities where not necessarily associated to fertility. The majority of sperm tail abnormalities found in Lusitano stallions falls in this latter category contrasting with Sorraia horses where, in addition, fertility rates are very poor. Indeed, this native Portuguese breed is considered by FAO (1998) as being in critical maintenance risk status; it suffers from a severe founder effect and presents a reduced genetic diversity, despite their closeness with other Iberian breeds (Luís et al., 2007).

Sperm cells membranes are sensible to cold-shock, a combination of factors that affect the integrity and functionality of the cell. In stallions this takes place between 19 and $8{ }^{\circ} \mathrm{C}$ (Moran et al., 1992). Our data suggest that, during storage, variability between individuals still occurs. Therefore, some male horses seem to have sperm cells that withstand better the low conservation temperatures than others. In PSL semen samples, 59\% of the variation found in sperm motility after dilution was explained by sperm motility after collection. Furthermore, sperm motility after dilution accounted for $9 \%$ of the variation found in sperm motility after $24 \mathrm{~h}$ of cool storage while sperm motility after collection only explained $3 \%$ of that variation.

Based on multifactorial analyzes of covariance the quantitative semen parameters gel free semen and sperm concentration did not influence fertility rates in any of the breeds. Among qualitative characteristics (sperm vitality and morphology) only in PSL stallions was a significant influence on fertility indicated by sperm vitality. Fertility rates seemed to be strongly influenced by progressive motile sperm after collection and semen pH in both breeds, in contrast with the report of Sieme et al. (2004).

In conclusion, we can state that Lusitano stallions have seminal traits which are similar to those of related breeds, except Sorraia horses, and present seminal traits compatible with artificial insemination and semen technologies. However, it is essential to properly handle spermatozoa so that the inherent semen quality of the stallion is preserved. This is especially important for the Sorraia breed, as poor sperm quality is compounded by poor preservation ability, both characteristics probably due 
to inbreeding in a limited population. Finally, while seminal evaluations are very useful to accurately define semen quality in a given stallion and for breeding management one or two ejaculates seem not to be enough to meet this goal.

\section{Acknowledgement}

Sandra Gamboa and Manuel Machado-Faria wish to thank all the staff of the Animal Reproduction Laboratory.

\section{References}

Allen, W.R., 2005. The development and application of the modern reproductive technologies to horse breeding. Reprod. Domest. Anim. 40, 310-329.

Amann, R.P., Thompson, D.L., Squires, E.L., Picket, B.W., 1979. Effect of age and frequency of ejaculation on sperm production and extragonodal sperm reserves in stallions. J. Reprod. Fertil. 27 (Suppl.), 1-6.

Aurich, C., Achmann, R., Aurich, J.E., 2003. Semen parameters and level of microsatellite heterozygosity in Noriker draught horse stallions. Theriogenology 60, 371-378.

Batellier, F., Vidament, M., Fauquant, J., Duchamp, G., Arnaud, G., Yvon, J.M., Magistrini, M., 2001. Advances in cooled semen technology. Anim. Reprod. Sci. 68, 181-190.

Bielański, W., Kaczmarski, F., 1979. Morphology of spermatozoa in semen from stallions of normal fertility. J. Reprod. Fertil. 27 (Suppl.), 39-45.

Bloom, E., 1950. A one minute live-dead sperm stain by means of eosin-nigrosin. Fertil. Steril. 1, 176-177.

Brinsko, S.P., Varner, D.D., 1993. Artificial insemination. In: McKinnon, A.O., Voss, J.L. (Eds.), Equine Reproduction. Williams \& Wilkins, Media, pp. 790-797.

Chapa, J., 1992. Manejo de Sementales. VI Jornadas Internacionales de Reproducción Animal e Inseminación Artificial. Livro de ponencias y mesas redondas. Salamanca, NIPO 251-92-067-2.

Dowsett, K.F., Pattie, W.A., 1982. Characteristics and fertility of stallion semen. J. Reprod. Fertil. 32 (Suppl.), 1-8.

Dowsett, K.F., Knott, L.M., 1996. The influence of age and breed on stallion semen. Theriogenology 46, 397-412.

FAO, 1998. Secondary Guidelines for Development of National Farm Animal Genetic Resources Management Plans. Management of Small Populations at Risk. Initiative for Domestic Animal Diversity. FAO, Rome.

France, 1992. Insémination Artificielle Équine, Guide Pratique. Ministère de L’Agriculture, de La Pêche et de l'Alimentation. Service des Haras, des Courses et de l'Equitation. Ed Institut du Cheval, 2e édition, France, 1996.

Foote, R.H., 2003. Effect of processing and measuring procedures on estimated size of bull sperm heads. Theriogenology 59, $1765-1773$.

Gamboa, S., Ramalho-Santos, J., 2005. SNARE proteins and caveolin-1 in stallion spermatozoa: possible implications for fertility. Theriogenology 64, 275-291.

Johnson, L., Varner, D.D., Tatum, M.E., Scrutchfield, W.L., 1991. Season but not age affects sertoli cell number in adult stallions. Biol. Reprod. 45, 404-410.

Klemetsdal, G., Johnson, M., 1989. Effect of inbreeding in Norwegian trotters. Lifestock Prod. Sci. 21, 263-272.

Luís, C., Bastos-Silveira, C., Costa-Ferreira, J., Cothran, E.G., Oom, M.M., 2006. A lost Sorraia maternal lineage found in the Lusitano horse breed. J. Anim. Breed. Genet. 123, 399-402.

Luís, C., Juras, R., Oom, M.M., Cothran, E.G., 2007. Genetic diversity and relationships of Portuguese and other horse breeds based on protein and microsatellite loci variation. Anim. Genet. 38, 20-27.

Malmgren, L., 1992. Sperm morphology in stallions in relation to fertility. Acta Vet. Scand. 88, 39-47.

Maroco, J., 2007. Statistical Analysis Using SPSS. 3a ed., Silabo, Lisbon.

Moran, D.M., Jasko, D.J., Squires, E.L., Amann, R.P., 1992. Determination of temperature and cooling rate which induce cold-shock in stallion spermatozoa. Theriogenology 38, 291-304.

Naden, J., Amann, R.P., Squires, E.L., 1990. Testicular growth, hormone concentrations, seminal characteristics and sexual behaviour in stallions. J. Reprod. Fertil. 88, 167-176.

Oom, M.M., 1992. The Lusitano Stallion. Ph.D. Dissertation, University of Lisbon, Lisbon, Portugal (Portuguese text).

Paccamonti, D.L., Buiten, A.V., Parlevliet, J.M., Colenbrander, B., 1999. Reproductive parameters of miniature stallions. Theriogenology 51, 1343-1349.

Parlevliet, J.M., Kemp, B., Colenbrander, B., 1994. Reproductive characteristics and semen quality in maiden Dutch Warmblood stallions. J. Reprod. Fertil. 101, 183-187.

Parlevliet, J.M., Colenbrander, B., 1999. Prediction of first season stallion fertility of 3-year-old Dutch Warmbloods with prebreeding assessment of percentage of morphologically normal live sperm. Equine Vet. J. 31, 248-251.

Pattie, W.A., Dowsett, K.F., 1982. The repeatability of seminal characteristics of stallions. J. Reprod. Fertil. 32 (Suppl.), 9-13.

Picket, B.W., 1993a. Factors affecting sperm production and output. In: McKinnon, A.O., Voss, J.L. (Eds.), Equine Reproduction. Williams \& Wilkins, Media, pp. 689-704.

Picket, B.W., 1993b. Reproductive evaluation of the stallion. In: McKinnon, A.O., Voss, J.L. (Eds.), Equine Reproduction. Williams \& Wilkins, Media, pp. 755-768.

Rodriguez-Martinez, H., 2003. Laboratory semen assessment and prediction of fertility: still utopia? Reprod. Domest. Anim. 38, 312-318.

Royo, L.J., Alvarez, I., Beja-Pereira, A., Molina, A., Fernández, I., Jordana, J., Gómez, E., Gutiérrez, J.P., Goyache, F., 2005. The origins of Iberian horses assessed via mitochondrial DNA. J. Hered. 96, 663-669. 
Sieme, H., Katila, T., Klug, E., 2004. Effect of semen collection practices on sperm characteristics before and after storage and on fertility of stallions. Theriogenology 61, 769-784.

Squires, E.L., Picket, B.W., Amann, R.P., 1979. Effect of successive ejaculation on stallion seminal characteristics. J. Reprod. Fertil. 27 (Suppl.), 7-12.

Thompson, D.L., Picket, B.W., Squires, E.L., Amann, R.P., 1979. Testicular measurements and reproductive characteristics in stallions. J. Reprod. Fertil. 27 (Suppl.), 13-17.

van Eldik, P., van der Waaij, E.H., Ducro, B., Kooper, A.W., Stout, T.A.E., Colenbrander, B., 2006. Possible negative effects of inbreeding on semen quality in Shetland pony stallions. Theriogenology 65, 1159-1170.

Voss, J.L., Squires, E.L., Pickett, B.W., Shideler, R.K., Eikenberry, D.J., 1982. Effect of number and frequency of inseminations on fertility of mares. J. Reprod. Fertil. 32 (Suppl.), 53-57. 